\title{
Study on Training Mode of Promoting Undergraduates' Innovation and Entrepreneurial Ability with Subject Competition
}

\author{
Longbin Liu ${ }^{1, ~ a}$, Fan Hu ${ }^{1, b}$, Zhenyu Jiang ${ }^{1, ~ c, ~}$, Haiyang $\mathrm{Xu}^{2, \mathrm{~d}}$ \\ ${ }^{1}$ College of Aerospace Science and Engineering, National University of Defense Technology, Deya Road, \\ Changsha, 410073, China \\ ${ }^{2}$ Military Basic Education College, National University of Defense Technology, Fuyuan Road, Changsha, \\ 410000, China \\ a longbuaa@163.com, ${ }^{\mathrm{b}}$ hufan_nudt@126.com, ${ }^{\mathrm{c}}$ jiangzhenyu00@yeah.net, ${ }^{\mathrm{d}}$ haiyangxuu@163.com \\ *corresponding author
}

Keywords: Subject competition; Innovation and entrepreneurship; Teaching reform; Comprehensive quality

\begin{abstract}
Subject competition is an important way to cultivate college students' innovation and entrepreneurship ability, which has a very positive effect on improving college students' innovative ability and comprehensive quality. However, with the increasing of subject competition subjects and the scale expansion, the problems faced are becoming more and more prominent. This paper explores three aspects of student subject competition project matching, teacher competition guidance, competition project entry, which makes the subject competition promote college students' innovation and entrepreneurship. The teaching mode innovation of ability cultivation aims to enhance the theoretical knowledge of undergraduates combined with the innovative and entrepreneurial ability of engineering practice, and stimulate students' innovative thinking and explore the ability to solve new problems, meanwhile, the new mode promotes the interest, initiative and enthusiasm of students to learn theoretical knowledge in the classroom and to improve students' comprehensive ability of scientific technical material writing, communication and coordination, teamwork, and learning self-confidence, etc, which has important implications and guiding significance for innovative talents cultivation for college students and for the improvement of students' innovation entrepreneurship ability and the education quality.
\end{abstract}

\section{Introduction}

With the continuous and rapid development of subject competition types and levels in various subjects across the country, different subject competitions of college students (national, provincial, municipal, and university level) have received more and more attention and participation from college students[1-6], but they were also facing many problems including the management of subject competition, imperfections, lagging competition incentives, lack of experience, weak awareness of competition subjects, and lack of propaganda. Li [7] studied some problems in the subject competition management and operation mechanism in colleges and universities, which needed to establish a reasonable management system and formulate and implement a sound management system to establish an effective operating mechanism to build a strong supporting platform. Li Juan [8] discussed the management and operation modes of subject competitions in universities, and researched to construct improving subject competition systems, and made subject competitions an effective way to cultivate innovative talents in universities. A et al [9] proposed the combination of subject competition and practical teaching to strengthen the construction of innovation and practice bases about related incentives and constraints to promote the cultivation of innovative talents. Wang Lei [10] further studied the establishment of a comprehensive and hierarchical subject competition system to make the subject competition become an effective method for innovative personnel training and practical teaching reform, and it expanded the scope of student innovation and entrepreneurship practice activities to achieve the promotion of personnel 
training system. Gao [11] explored the ways to improve college students' innovative ability through subject competition under the new situation, which also studied factors that affected college students to participate in subject competitions. Sun [12] believed that the subject competition was an important way to cultivate students' innovative practical ability and an important guarantee for improving teaching quality. In the current background of "many innovations and popular entrepreneurship", there was an urgent need to establish an effective competition management mechanism and personnel training, and the model proposed a six-in-one local application-type college subject competition talent training model. Chen [13] discussed the practical issues of subject competition and education reform from the perspective of collaborative innovation, and proposed a multi-level basic principle, a cross-subjectd integration of teaching models, and a development path for multi-path training systems to promote innovative personnel training in schools. so that students actively participated in and stimulated students' potential to accelerate the growth of students' selfdevelopment [2, 9, 14-16].

The subject competition is widely carried out in the current teaching reform background, this paper combines the cognition of the subject competitions of undergraduates, and studies the content of subject competitions including student subject competitions, teacher competition guidance, and entry into competition events to improve the theoretical knowledge of university students. And combining engineering practice with innovation and entrepreneurship, inspiring students' creative thinking in science and exploring the ability to solve new problems, this mode advances teaching model innovation that promotes the cultivation of undergraduates' innovative and entrepreneurial abilities through subject competitions, which could foster innovative talents for college students and improve students' abilities in innovation and entrepreneurship. And it has important practical reference for implementing the education curriculum system reform quality.

\section{Student Subject Competition Matches}

Since the level of knowledge and hands-on practice of undergraduates are different, the difficulty of practical projects that are suitable for student competitions are also uneven. For students with different levels of comprehensive ability, it is crucial to choose the right match project, which would even directly affect the enthusiasm of the students to carry out the subject competition project research and the effectiveness of the final competition. The matching of student subject competition projects is an initial part of students participating in subject competitions and teacherdirected teaching activities. Subject competition projects are effective carriers for improving students' innovation and entrepreneurship practice ability and comprehensive quality. In order to improve the effectiveness of students participating in the subject competition, they need to be targeted first. And the match study of student subject competition projects and students' individual differences in the ability is performed to let students participate in the subject of competition project research in their own interest.

The implementation process of student subject competition matching project is shown in Figure 1 , the student subject competition project can be from the students' own reflection on the problems seen in life with concise innovation point, analysis of technically achievable degree of difficulty, and feasibility analyse, and then students could combine the comprehensive strength of self or team's participating subject competition to form the interesting innovation subject contest project that they wants to solve. If the student does not have a research question of interest, he can choose one among the subject competition projects provided by the instructor or the instructor directly assigns the student a competition research topic. Of course, the subject competition projects provided by the instructor should include different levels of innovation, which could meet the student's choice of learning to participate in subject competition projects. The competition research topic assigned by instructors should consider the level of students' knowledge and hands-on skills, and the instructors should also provide management, technical guidance, and necessary financial support for the entire project. 


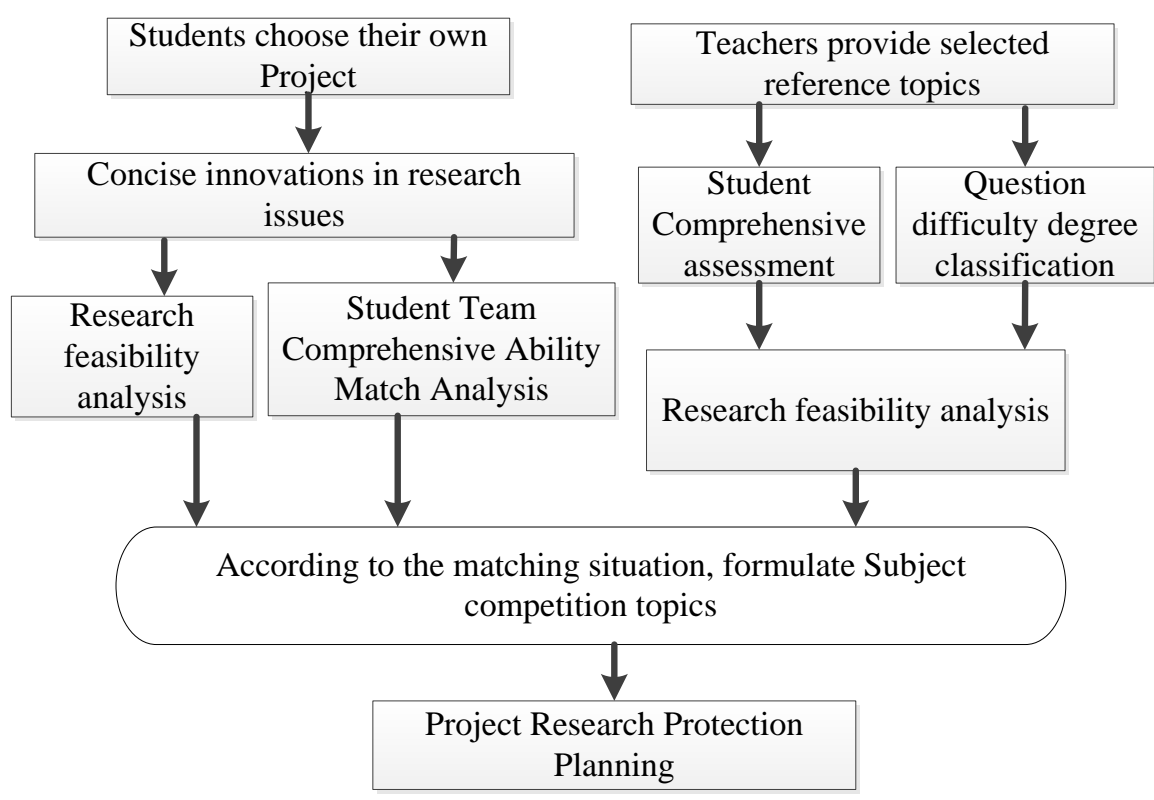

Figure 1 The implementation process of student subject competition matching project

According to the matching situation of the student team's comprehensive ability and the optional subject competition project, the instructor and the participating students shall further communicate and coordinate to initially draft the research topics involved in the subject competition. The instructor provides the participating students or teams with preliminary protection conditions for the research topics subjects, such as the venue of the research topic, experimental testing equipment, material costs, research, hands-on tools, etc., which provides basic guidance for teachers in all follow-up aspects and student competitions.

\section{Teacher Competition Guide}

The teacher competition instruction needs all-round participation and timely understanding of the dynamic process, and the teachers should timely answer students' various problems appeared in the project implementation process. Taking the example of the subject competition project "Design and Experimental Study of Flexible Inflatable Wings" for undergraduate students of our university, and the teacher competition guidance process is shown in Figure 2.

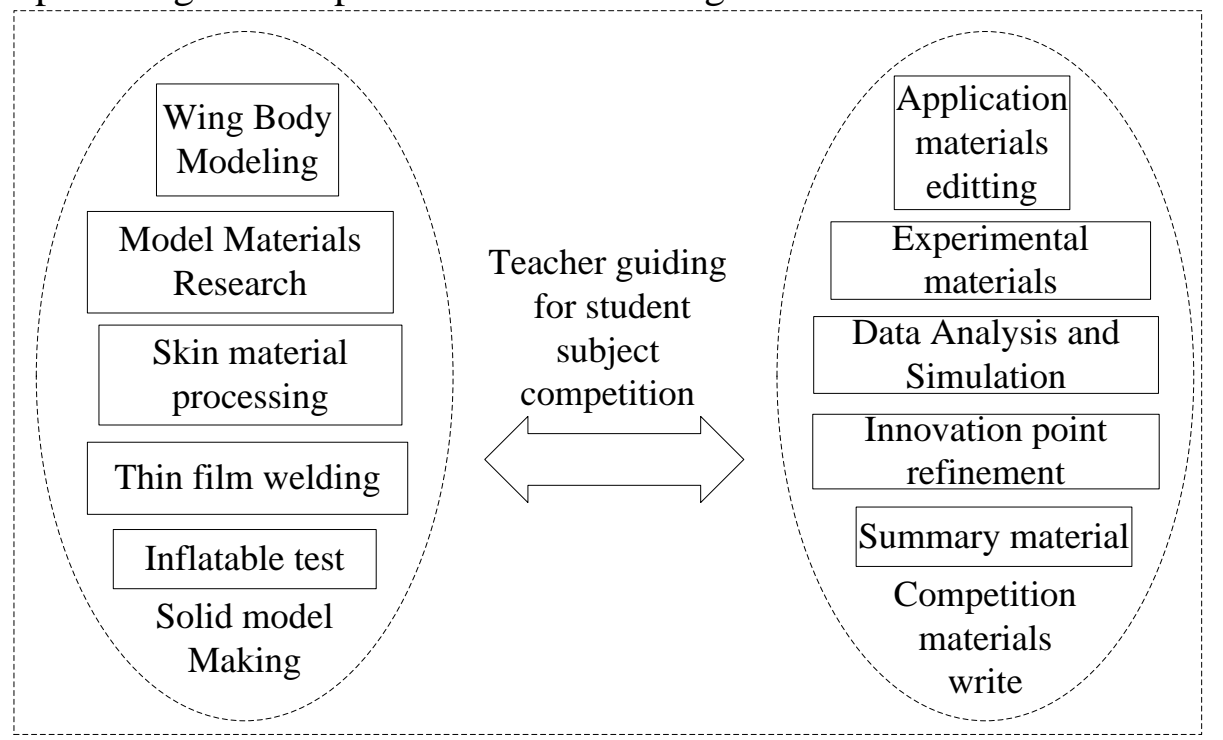

Figure 2 The full process of teacher's guide to student subject competition

\subsection{Solid Model Making}

The production of the physical model of the research project is an important part of the student's 
participation in subject competition practice activities, and it is also a key link in cultivating and training students' hands-on practical operation ability and overall quality. Taking the design of flexible aerated wing and experimental research as an example, solid modelling includes modelling wing solids, model material research, material processing and cutting, skinning film welding, and gas filling tests. Because of lack of engineering experience, the instructors need to guide the whole process of tracking the production of solid models. For the problems encountered by students in the process of creating the competition model, the instructors give enough advice or suggestions.

The instructors guide students to study solid modelling software in advance and to master the basic skills of using software, and also to train students to draw inflated wing 3D solid models according to their own or the team's vision. And the proposed parameter project requirements based on the basic theoretical knowledge learned in the classroom, students could determine the material composition of the components of the inflating wing and specify the optional process plan. Further they could review the data, investigate the required materials, and determine the material parameters and the skin material processing and melding process. Then according to the characteristics of the inflating wing skin material, the participating team members cooperate in the division of labour, and perform cutting and welding on the wing skin film material. After the entire wing is formed, the instructors guide the student in advance to inflate the wing's inflation test characteristics as well as informing the students about possible problems and test considerations through discussion meetings, which provides a favourable guarantee for the implementation of student subject competition projects.

The teacher instructs students in the physical modelling of the subject competition project and cultivates the students' abilities to use theoretical knowledge to solve practical problems, which helps students to solve the practical problems encountered in the hands-on operation and model making process in time, and enhance students' interest in participating in the subject competition. And self-confidence has been improved with the students' ability to study independently and solve problems, and students' engineering practice operation skills has been trained as well, which lays the foundation for the overall improvement of students' overall quality.

\subsection{Student Competition Materials Writing}

The participating students need to consolidate innovative functions and write contest submission materials based on the physical models and experimental results produced, which will help students improve their writing ability in science and technology materials, and exercise their comprehensive ability in integrating written materials, pictures, video materials, and language organization. Still taking the subject competition project of flexible aerated wing design as an example, the writing of student entry materials includes the editing of application materials, the collation of experimental results, data analysis and simulation calculations, the refinement of competition innovation points, and the summation of integration materials. Students' teamwork skills are also cultivated and trained with the students' writing skills improving.

It is a very complicated process for instructing teachers to train students participating to write entry materials, and the materials requires the cyclical modification. Based on the individual or team competition project indicators, the participating students will initially compile the contest application materials and learn to analyse the physical model experimental data according to the individual or team competition project indicators. Sometimes, the numerical simulation results may also be used in research to explore the deformation characteristics of the aerated pneumatic wing flow field. With the inflating wing carrying the deformation law, refining the innovation of the competition project or the innovative function produced from the solid model, or some practical problems involving to solve in life or engineering. The innovation of the competition materials should clearly point out that, for example, the inflator wing has the function of small folding volume and rapid inflation, which realizes many innovative functions such as small volume storage, loading, transportation, and rapid response.

The teacher guides the student in writing the entry materials, discovers and modifies the inadequacies of the student's written contest materials in different stages, and promptly proposes 
opinions and suggestions to the students or student team members, and uses the writing of the subject competition project as a link to improve student writing. The level and ability of science and technology materials have also gradually improved students' ability to discover new problems, to solve new problems, and to summarize data analysis. Instructors are involved in the preparation of the physical model of the student subject competition project and the writing of entry materials throughout the entire process to ensure the smooth implementation of student subject competition projects.

\section{Competition Project Participation}

According to the physical model and written application materials, the students conduct subject competitions in order to better display the advantages and features of the participating subject competition project works to the expert judges, and it is necessary to concise and summarize the innovative highlights of the participating project works combining with the experimental results of the physical model. Highlighting the innovative features should be realized in the parametric project works and explore potential future market application prospects and social economic benefits.

Instructing students to participate in the competition is the final demonstration of the student subject competition, which also encourages the use of diverse formats such as videos, animations, ppts, research reports, etc. to focus on the innovative highlights and innovative features of the participating projects, meanwhile the student self-comprehensive ability of performance should be cultivated, and the timely amendment of the students' participating materials could help students understand the market application value and prospects of the parametric project works. The summary can be used as a support point for the implementation of innovation and entrepreneurship, which let students to focus on social economic developments in the fields related to the entry project works, and it also provides an effective way for students to better adapt to social work and improve their overall ability.

Through the student subject competition teaching practice in recent years, the undergraduate competition team that has been instructed has obtained one school-level first, second and third prize, two provincial second-level competition prizes, and five provincial third-level prize. The project has won one second prize at the national level and has achieved good teaching results through the subject competition to promote students' innovation and entrepreneurship ability.

\section{Conclusion}

The matching of the student subject competition project effectively achieves the match between the subject competition project and the student's individual difference ability, which helps increase the initiative and enthusiasm of the students to participate in the subject competition project that they are interested in. And it provides strong protection for student subject competition project implementation.

The teacher participates in the whole process of guiding students in the production of physical models and the writing of entry materials, and comprehensively exercised the students' abilities to apply theoretical knowledge to solve practical problems. This helpes students solve the practical problems encountered in the hands-on operation and model making process in time, and enhance student participation interest and self-confidence of the subject competition, which has improved students' ability to study independently and to solve problems.

Students participate in the competition project entries, which helps develop the students' selfexpression comprehensive ability, and learn to adapt to the social environment, and improve the students' ability of innovation and entrepreneurship and comprehensive quality. And it finally promotes the students' innovative and entrepreneurial ability training in the subject competition.

\section{Acknowledgements}

The research was sponsored by the Research project of National University of Defense 
Technology (No. ZK16-03-33) and Hunan Natural Science Foundation (No. 2018JJ3591), as well as Hunan Provincial Degree and Graduate Education Teaching Reform (JG2016B004) and the National University of Defense Technology Education Teaching Research Project (U2016001).

\section{References}

[1] Deng, Y. M., Ding, N. (2017) Study on the Management System of College Students 'Subject Competition. Science and Technology Innovation Herald, 14, 223-224. (in Chinese)

[2] Xia, L. N. (2014) Analysis on the Problems of Subject Contests at Local Universities. Journal of Zhejiang Ocean University (Hu-manities Science), 31, 81-84. (in Chinese)

[3] Lu, G. D., Chen, L. Q., He, Q. M., et al. (2018) The Evaluation of Subject Competition in Universities: Plan, Method and Exploration. Study on Higher Education in China, (02), 63-68+74. (in Chinese)

[4] Fan, L., Ding, Z. Y., Tang, X., et al. (2016) On Construction of Multi-disciplinary Competition Platform for Cultivating Practical Innovative Talents. Journal of Southwest China Normal University (Natural Science Edition), 41, 178-182. (in Chinese)

[5] Zheng, M. H. (2017) Research on the Cultivation of College Students’ Innovation Ability Based on the Subject Competition. Future and development, 41, 105-108. (in Chinese)

[6] Lv, X. X. (2017) On the Cultivation Model of College Students 'Creative Ability Based on Subject Competition. Science \& Technology Vision, (36), 64+72. (in Chinese)

[7] Li, J. H., Liu, C. L. (2010) Discussion on Ad-ministration and Operation Mechanism of Subject Contests. Journal of Hunan Institute of Humanities Science and Technology, (03), 119-121. (in Chinese)

[8] Li, J., Liu, J. (2012) Discussion on the Management and Operation Model of the Subject Competition. Education and occupation, (05), 149-151. (in Chinese)

[9] Ayxam·Aili. (2017) Strengthen the Platform Construction of Subject Competition to Cultivate the Innovative Talents. Education Teaching Forum, (45), 110-112. (in Chinese)

[10] Wang, L., Zhan, S. C. (2016) The Construction and Practice of Subject Competition System with Full Participation and Hierarchy. Journal of Baicheng Normal University, 30, 51-53+76. (in Chinese)

[11] Gao, Y. T., Ren, B. L., Ma, Q. Q. (2017) How to improve the innovation ability of college students through subject competition. Read and Write Periodical, 14, 33. (in Chinese)

[12] Sun, K. C., Chen, H. B., Yang, B. et al. (2017) Exploring the Cultivation Mode of the Personnel in the Competition of Local Applied Colleges and Universities. Journal of Shanxi Xueqian Normal University, 33, 113-116. (in Chinese)

[13] Chen, H. S. (2017) On the development of subject competition under the angle of collaborative innovation. Journal of Northwestern Polytechnical University (Social Sciences), 37, 70-72. (in Chinese)

[14] Liu, H. M., Hu, R. (2017) The Cultivation of the Practice and Innovation Ability of Mechanical College Students in the Subject Competition. Light Industry Science and Technology, 33, 166-167. (in Chinese)

[15] Xu, K., Geng, W. B., Zhou, Z. A., et al. (2016) Constructing a New Mode of ApplicationOriented Talent Cultivating Through Subject Contest. Journal of Zhoukou Normal University, 37, 70-72. (in Chinese)

[16] Liu, L., Sun, L. P., Zhang, H. T., et al. (2014) Construct Subject Competition, Cultivate Creative Talents. Journal of Changsha University, 28, 135-137. (in chinese) 